\title{
CONGENITAL MALFORMATION IN STILLBIRTHS- A HOSPITAL BASED STUDY
}

\author{
Siddharth Hazarika1 ${ }^{1}$ Giriraj Kusre ${ }^{2}$
}

${ }^{1}$ Demonstrator, Department of Anatomy, Assam Medical College, Dibrugarh, Assam.

${ }^{2}$ Associate Professor, Department of Anatomy, Assam Medical College, Dibrugarh, Assam.

ABSTRACT

\section{BACKGROUND}

Globally 2.6 million stillbirths occur every year with three fourth of them occurring in south Asia and sub-Saharan Africa. Congenital malformations are a major cause of stillbirths. No studies have been carried out in Northeast India to assess the relative importance of congenital malformation and stillbirths. Hence, the present study was undertaken.

\section{MATERIALS AND METHODS}

The study was a descriptive study. Information from parents of stillbirths were collected in a structured proforma prepared as EUROCAT, 2005 with local modification. Detailed autopsy of the stillbirth was carried out in the Department of Anatomy. Congenital malformations were classified according to the ICD-10 classification.

\section{RESULTS}

Congenital malformation was seen in $16(14.95 \%)$ stillbirths. 56.25\% (N=9) were female and one foetus had Ambiguous genitalia. $62.5 \%(\mathrm{~N}=10)$ were preterm births and $37.5 \%(\mathrm{~N}=6)$ had low birth weight. Multiple system involvement was the most common (37.5\%) malformation and total 41 types of individual malformations were observed.

\section{DISCUSSION}

Congenital malformations are a major cause of stillbirths and infant mortality. Around 20\% of stillbirths are observed to have detectable congenital malformation. The probable reason for multisystem involvement and Encephalocoele and Omphalocoele type of congenital malformation among stillbirths was due to defects having intrinsic origin.

\section{CONCLUSION}

Congenital malformation is one of the most common cause of stillbirths. Preterm delivery and Low birth weight are commonly associated with stillbirth with congenital malformation. Multiple systems involvement and severe malformation such as Encephalocoele and Omphalocoele were the most common malformation observed among stillbirths.

\section{KEYWORDS}

Stillbirth, Congenital Malformation.

HOW TO CITE THIS ARTICLE: Hazarika S, Kusre G. Congenital malformation in stillbirths- a hospital based study. J. Evolution Med. Dent. Sci. 2017;6(88):6109-6111, DOI: 10.14260/jemds/2017/1327

\section{BACKGROUND}

ICD-10 classifies late foetal deaths as death of foetus greater than $1000 \mathrm{~g}$ or after 28 weeks, ${ }^{1}$ Late foetal deaths are often termed as 'stillbirth'. The definition of stillbirth recommended by WHO for international comparison is a 'baby born with no signs of life at or after 28 weeks' gestation'.2 In 2015, there were 2.6 million stillbirths globally, with more than 7178 deaths a day. The majority of these deaths occurred in developing countries. Three-fourth of the stillbirths occurred in south Asia and sub-Saharan Africa and 60\% occurred in rural families from these areas. ${ }^{2}$

Congenital malformation are a major cause of stillbirths and infant mortality and the aetiology of most is not fully understood. ${ }^{3}$ In developed countries, it contributes to nearly a quarter of deaths. ${ }^{4}$

'Financial or Other Competing Interest': None.

Submission 17-09-2017, Peer Review 22-10-2017,

Acceptance 28-10-2017, Published 06-11-2017.

Corresponding Author:

Dr. Giriraj Kusre,

Associate Professor,

Department of Anatomy,

Assam Medical College,

Dibrugarh, Assam.

E-mail: giriraj_kusre@rediffmail.com

DOI: $10.14260 /$ jemds/2017/1327

\section{(C)}

No studies have been carried out in northeast India to assess the relative importance of congenital malformation and stillbirths. The present study is an attempt to determine the pattern of congenital malformation in stillbirth foetuses born in the Department of Obstetrics and Gynaecology of a referral Medical College and Hospital from Northeast India.

\section{MATERIALS AND METHODS}

The study was a descriptive study, carried out in the Department of Anatomy of a referral Medical College and Hospital of Northeast India region from June 2015- May 2016. Stillbirths born in the labour room of the Department of Obstetrics and Gynaecology of the hospital with gestational age beyond 28 weeks and foetal weight more than $1000 \mathrm{~g}$ were defined as cases. All macerated foetuses where consents for dissection were not given were excluded from the study. Permission from institutional ethical committee (Human) was obtained before initiation of the study.

Information from parents was collected in a structured proforma prepared as EUROCAT 2005 with local modification. Detailed autopsy was carried out in the Department of Anatomy. For the study stillbirth was defined as any foetal death weighing at least $1000 \mathrm{~g}$ or a gestational age of 28 completed weeks. Term pregnancy was defined as pregnancy from 37 completed weeks of gestation up to 42 weeks of gestation. Low birth weight was defined as weight less than 
2500 g. Congenital malformations were classified according to the ICD-10 classification. All those foetuses, where more than one system was involved, were classified as multisystem involvement. Each malformation was again classified individually.

\section{RESULTS}

After observing all the selection criteria of foetus for the study, a total 107 stillbirths were procured from the Department of O\&G. After gross observation and dissection, congenital malformation was seen in $16(14.95 \%)$ of them. $56.25 \%(\mathrm{~N}=9)$ and $37.5 \%(\mathrm{~N}=6)$ were male and female respectively, one foetus had Ambiguous genitalia. 62.5\% ( $\mathrm{N}=10)$ were preterm births and $37.5 \%(\mathrm{~N}=6)$ had low birth weight. Multiple system involvement was the most common (37.5\%) system involved and total 41 types of individual malformations were observed (Table 1).

\begin{tabular}{|c|c|c|}
\hline Type of malformation & ICD Code & Number \\
\hline \multicolumn{3}{|c|}{ CNS Q $00.0-07(\mathrm{~N}=4)$} \\
\hline Encephalocoele & $\mathrm{Q} 01.8$ & 4 \\
\hline \multicolumn{3}{|c|}{ Eye, Ear Face and Neck Q10-18 (N=8) } \\
\hline Right cleft nasolacrimal duct & $\begin{array}{c}\text { Q10.6 } \\
\text { (unspecified) }\end{array}$ & 2 \\
\hline Agenesis of left eye & $\mathrm{Q} 11.1$ & 1 \\
\hline Cryptophthalmos & Q11.2 & 1 \\
\hline Exophthalmos & Q15.8 & 1 \\
\hline Pterygium colli & Q18.3 & 1 \\
\hline Microstomia & Q18.5 & 2 \\
\hline \multicolumn{3}{|c|}{ Circulatory system $\mathrm{Q} 20-\mathrm{Q} 28(\mathrm{~N}=1)$} \\
\hline Ectopia cordis & $\mathrm{Q} 24.8$ & 1 \\
\hline \multicolumn{3}{|c|}{ Respiratory system $\mathrm{Q} 30-34(\mathrm{~N}=4)$} \\
\hline $\begin{array}{c}\text { Congenital stenosis of anterior } \\
\text { nares }\end{array}$ & Q 30.0 & 2 \\
\hline Congenital absence of nose & Q30.1 & 1 \\
\hline Hypoplasia of lungs on both side & Q33.6 & 1 \\
\hline \multicolumn{3}{|c|}{ Cleft lip and cleft palate Q35-Q37 $(\mathrm{N}=4)$} \\
\hline Cleft lip median & Q36.1 & 1 \\
\hline Cleft lip, unilateral & Q36.9 & 2 \\
\hline Cleft palate with cleft lip & Q37.9 & 1 \\
\hline \multicolumn{3}{|c|}{ Digestive system Q38-Q45 $(\mathrm{N}=2)$} \\
\hline Macroglossia & Q38.2 & 1 \\
\hline Imperforate anus & $\mathrm{Q} 42.3$ & 1 \\
\hline \multicolumn{3}{|c|}{ Genitourinary system Q50-Q64 (N=6) } \\
\hline Undescended teste, unilateral & QQ53.1 & 1 \\
\hline Phimosis & Q55.8 & 1 \\
\hline Ambiguous genitalia & Q56.4 & 1 \\
\hline Hydronephrosis left kidney & Q62.0 & 1 \\
\hline congenital dilatation of ureter & Q62.2 & 1 \\
\hline $\begin{array}{c}\text { Urinary bladder outlet } \\
\text { obstruction }\end{array}$ & Q64.3 & 1 \\
\hline \multicolumn{3}{|c|}{ Musculoskeletal system Q65-Q7 (N=11) } \\
\hline CTEV & Q66.0 & 2 \\
\hline Right-sided thumb missing & Q71.3 & 1 \\
\hline Amelia & Q73.0 & 1 \\
\hline Congenital malformation of limbs & $\begin{array}{c}\text { Q74.9 } \\
\text { (unspecified) }\end{array}$ & 2 \\
\hline Hypertelorism & Q75.2 & 1 \\
\hline Sternum bifidum & Q76.7 & 1 \\
\hline Omphalocoele & Q79.2 & 3 \\
\hline \multicolumn{3}{|c|}{ Other congenital malformations Q80-89 (N=1) } \\
\hline Hydrops fetalis & Q89.8 & 1 \\
\hline Grand total & & 41 \\
\hline $\begin{array}{r}\text { Table 1. Classification Accor } \\
\text { Malforma }\end{array}$ & $\begin{array}{l}\text { ling to the Indi } \\
\text { ion }\end{array}$ & idual \\
\hline
\end{tabular}

\section{DISCUSSION}

Congenital malformations are a major cause of stillbirths and infant mortality. ${ }^{3}$ Around $20 \%$ of stillbirths are observed to have detectable congenital malformation. ${ }^{5}$ In three different studies from India, $6,7,8$ the rate of congenital malformation among the stillbirths was observed to be as $20.4 \%, 12 \%$ and $9.8 \%$ respectively. ICD-10 defines stillbirth as "death prior to complete expulsion or extraction from its mother of a product of conception, irrespective of the duration or pregnancy, the death is indicated by the fact that, in such separation the foetus does not breathe or show any other evidence of life, such as beating of the heart, pulsation of the umbilical cord, or definite movement of voluntary muscles". WHO recommends inclusion of all foetuses born dead weighing more than $1000 \mathrm{~g}$ or after completion of 28 weeks of gestation. ${ }^{1}$ In the present study, the percentage of malformation was observed to be in $14.95 \%$ of stillbirths. The difference in rate of congenital malformation in different studies was probably due to differences in study population, sample size or due to difference in definition. Inability to differentiate the dead foetus from foetus dying immediately after birth may be some of the causes for difference in rate of congenital malformation in stillbirth.

In the present study, $62.5 \%(\mathrm{~N}=10)$ of stillbirths with congenital malformation were preterm births. An adverse pregnancy outcome, that is closely linked to preterm birth, is stillbirth. ${ }^{1}$ In a study carried out by the author in the same hospital, about $54.38 \%$ of stillbirth were premature. ${ }^{9}$ In studies from Sweden, most stillbirths could be attributed to an aetiology. In those studies, more than $50 \%$ of stillbirths had identified aetiology including congenital malformation. ${ }^{10}$ In a retrospective study, stillbirth rate among ultrasound detected anomalous stillbirth was 55 per 1,000 compared with 4 per 1,000 in non-anomalous foetuses. Stillbirth risk among anomalous preterm foetuses before 32 weeks of gestation was $26 / 1,000$ and 32 weeks of gestation or after was $31 / 1,000$. Even among growth-restricted foetuses, the stillbirth rate increased among anomalous foetuses $(127 / 1,000)$. Congenital anomalies remained associated with higher rates of stillbirth. ${ }^{11}$

In the present study, $37.5 \%(\mathrm{~N}=6)$ of stillbirths with congenital malformations had low birth weight. In a study from rural India, stillbirths and LBW were significantly associated with congenital malformations. ${ }^{12}$ Stillbirth occurs due to low survival potential of a LBW foetus and congenital malformation by its effect on growth restriction may contribute stillbirth through LBW.

Individual malformations and stillbirth- Martínez-Frías $\mathrm{ML}^{13}$ observed that there were three different types of deformation sequences, the first sequence is with polyhydramnios, thin skin without dermal ridges, hypotonia, and multiple deformations (hypokinesia sequence), which is most often due to intrinsic problems; and other sequences are with oligohydramnios and normal amniotic fluid volume, producing deformities of extrinsic origin. Deformations of extrinsic cause are more frequently isolated defects and have a better prognosis, while deformations of intrinsic origin are more frequently associated with other multiple anomalies and generally have a poor prognosis. In the present study, multiple system involvement (37.5\%) was most commonly seen among stillbirths and musculoskeletal malformation $(68.75 \%, \mathrm{~N}=11)$ was the most common individual system to be involved. Encephalocoele $(\mathrm{N}-4)$ and Omphalocoele $(\mathrm{N}=3)$ were the most 
common individual malformation seen among stillbirths. The Probable reason for multisystem involvement and Encephalocoele and Omphalocoele type of congenital malformation among stillbirths was due to defects having intrinsic origin.

\section{CONCLUSION}

Congenital malformation is one of the most common cause of stillbirths. Preterm delivery and low birth weight are commonly associated with stillbirth with congenital malformation. Multiple systems involvement and severe malformation such as Encephalocoele and Omphalocoele were the most common malformation observed among stillbirths.

\section{ACKNOWLEDGEMENT}

We acknowledge the support provided by the staff and residents of 0\&G Department of Assam Medical College, Dibrugarh.

\section{REFERENCES}

[1] Lawan JE, Gravett MG, Nunes TM, et al. Global report on preterm birth and stillbirth (1 of 7): definitions, description of the burden and opportunities to improve data. BMC Pregnancy and Childbirth 2010;(Suppl 1):S1.

[2] WHO

http://www.who.int/maternal_child_adolescent/epid emiology/stillbirth/en/ on 13.09.17

[3] Rankin J, Pattenden S, Abramsky L, et al. Prevalence of congenital anomalies in five British regions, 1991-99. Archieves of Disease in Childhood Fetal and Neonatal Edition 2005;90(5):F374-F9.

[4] McClure EM, Saleem S, Pasha O, et al. Stillbirth in developing countries: a review of causes, risk factors and prevention strategies. J Matern Fetal Neonatal Med 2009;22(3):183-90.
[5] Reddy UM, Goldenberg R, Silver R, et al. Stillbirth classification-developing an international consensus for research: executive summary of a National Institute of Child Health and Human Development Workshop. Obstet Gynaecol 2009;114(4):901-14.

[6] Purandare VN, Stevenson AC, Johnston HA, et al. Congenital malformations - a report of a study of congenital births in 24 centres. Bull WHO 1966;(Suppl 34): p. 24.

[7] Mathur BC, Karan S, Devi VKK. Congenital malformations in newborn. Indian Journal of Pediatrics 1975;12(2):179-83.

[8] Chaturvedi P, Banerjee KS. Spectrum of congenital malformations in the newborns from rural Maharashtra. Indian Journal of Pediatrics 1989;56(4): 501-7.

[9] Baruah J, Kusre G, Hazarika S. Profile of stillbirths in a referral hospital from North-east India - a record based study. J Evolution Med Dent Sci 2017;6(21):1683-6.

[10] Gravett MG, Rubens CE, Nunes TM, et al. Global report on preterm birth and stillbirth (2 of 7): discovery science. BMC Pregnancy and Childbirth 2010;10(Suppl 1):S2.

[11] Frey HA, Odibo AO, Dicke JM, et al. Stillbirth risk among fetuses with ultrasound-detected isolated congenital anomalies. Obstet Gynecol 2014;124(1):91-8.

[12] Taksande A, Vilhekar K, Chaturvedi P, et al. Congenital malformations at birth in Central India: a rural medical college hospital based data. Indian J Hum Genet 2010;16(3):159-63.

[13] Martínez-Frías ML, Bermejo E, Frías JL. Analysis of deformations in 26,810 consecutive infants with congenital defects. Am J Med Genet 1999;84(4):365-8. 